\title{
ASSESSMENT OF THE IMPACT OF OXIDATIVE STRESS ON FROZEN SEMINAL PLASMA IN FERTILE AND INFERTILE MEN BY EXAMINING THE TOTAL ANTIOXIDANT CAPACITY
}

\author{
Violeta S. Rilcheva ${ }^{1}$, \\ Nina P. Ayvazova ${ }^{1,2}$, \\ Danail I. Martinov', \\ Cvetomir I. Ivanov ${ }^{1,2}$, \\ Emiliana I. Konova ${ }^{1,3}$
}

\section{${ }^{1} M C$ Clinical Institute for Reproductive Medicine - Pleven ${ }^{2}$ Institute of Biology and Immunology of Reproduction, Sofia \\ ${ }^{3}$ Center for Reproductive Health, Medical University - Pleven}

Corresponding Author:

Violeta S. Rilcheva

e-mail:dr.rilcheva@gmail.com

Received: May 20, 2014

Revision received: September 18, 2014

Accepted: November 24, 2014

\section{Summary}

The aim of the study was to explore the impact of oxidative stress on frozen seminal plasma in fertile and infertile men by examining the total antioxidant capacity. Patients: Infertile patients from male infertility clinic with various diagnoses and fertile men. Design: Seminal plasma from proven fertile men $[\mathrm{n}=50]$ and infertile patients $[n=50]$ were examined for total antioxidant capacity (TAC) level, semen parameters such as morphology, motility and concentration, and DNA integrity test. Interventions: Seminal plasma TAC measurement by luminometric assay using the TAC assay kit, semen analysis parameters, DNA integrity test. Fertile men showed higher TAC values (median and SD): $1201 \mu \mathrm{M}(\mathrm{SD} \pm 548)$, as compared with the infertile patients: $831 \mu \mathrm{M}(\mathrm{SD} \pm 343)$. The result from sperm morphology of fertile patients showed a mean percentage of $4.8 \%(\mathrm{SD} \pm 1.68)$ whereas the percentage in the infertile group was $2.68 \%(\mathrm{SD} \pm 1.68)$. The same group of samples, analyzed for DNA damage showed a mean of DFI $10.38 \%$ $(\mathrm{SD} \pm 5.17 \%)$ in fertile men and a mean of DFI $17.22 \%$ $(\mathrm{SD} \pm 7.22 \%)$ in infertile men. Total antioxidant capacity of the seminal plasma as measured by the luminometric assay is a reliable and simple test for diagnosing and management of male infertility.

Key words: seminal plasma, male infertility, oxidative stress, total antioxidant capacity

\section{Introduction}

Infertility is a term referring to a failure of a couple to achieve a pregnancy within one year of regular unprotected intercourse. Subfertility is registered in $10-15 \%$ of couples of reproductive age. In $30-50 \%$ of these couples, infertility is caused by male reproductive dysfunction, and disturbances are found in $26 \%$ of infertile couples.

Causes of male infertility are identified at various levels. The testes themselves may be affected; infertility may be due to impairments of excurrent seminal ducts or in the accessory sex glands, or there may be a disturbance of semen deposition. Impairment of central structures such as the hypothalamus and the pituitary or the androgen target organs may also result in subfertility [1]. 
Causes for male infertility include endocrine, urological, infectious genetic and other common problems with a complex etiology, and require a complete andrological diagnosis. The male reproductive tract is controlled by a well balanced hormonal system, with participation of hypothalamic $(\mathrm{GnRH})$, pituitary (LH, FSH) and testicular hormones (androgens, inhibin B).

Semen analysis includes sperm concentration, sperm motility, sperm morphology, sperm cell vitality, $\mathrm{pH}$ and leucocyte count. The benefits from determining these parameters as predictors of fertility appear to be rather limited. Alternative tests such as sperm penetration, capacitation, acrosome reaction are available but they have not been approved as standard procedures. Previous studies, including our own studies, have demonstrated that the assessment of DNA integrity by flowcytometry (DNA integrity test [SDI]), has better predictive value for pregnancy outcome by natural or assisted reproduction.

The functional capacity of sperm cells decreases in patients with testicular pathology, endocrinological and genetic diseases, etc. Generation of free radicals that can not be neutralized by the antioxidant protection of cells is assumed to be a major factor [2-7].

Seminal plasma contains the entire enzyme complex, providing antioxidant protection of sperm cells [8]. This protection compensates for the loss of cytoplasmic sperm enzymes during maturation and transportation processes [5, 6, 911]. The total antioxidant capacity of seminal plasma is provided by the enzymatic (e.g. superoxide dismutase, catalase, and glutathione peroxidase) and nonenzymatic systems (e.g. ascorbate, urate, vitamin E)

When TAC levels are low, oxidative stress causes damage to the spermatozoa, and this correlates with reduction in function in fertile men. It is believed that free radicals cause damage to sperm DNA. Several reports have related low seminal plasma TAC levels to male infertility in general, as well as to failure in intrauterine insemination and in vitro fertilization (IVF) [6, 13-17].

\section{Materials and Methods}

\section{Subject Selection}

This study was approved by the Ethics Committee of Medical University - Pleven. Infertile patients $(\mathrm{n}=50)$ as well as fertile healthy men $(n=50)$ were screened and selected on the basis of normal semen analysis according to the World Health Organization-2010 [18] guidelines. The mean age for the fertile group was 36.81 years $(\mathrm{SD} \pm 4.59)$ and 35.9 years $(\mathrm{SD} \pm 5.75)$ for the infertile group.

\section{Semen Collection and Preparation}

Semen sample were collected by masturbation after 3 to 7 days of sexual abstinence. After complete liquefaction at $36.6 \mathrm{C}^{0}$ for 30 minutes, and $5 \mu \mathrm{L}$ of each sample was loaded on an improved Neubauer counting chamber (Marienfeld superior, Germany) where conventional sperm analysis of concentration was carried out. Morphology was assessed, according to strict Kruger criteria, and motility was measured. All results were classified according the WHO, 2010 [18]. The infertile patient group $(\mathrm{n}=50)$ included men with a history of infertility of over one year of unprotected sexual intercourse. The fertile patients $(n=50)$ had achieved pregnancy less than one year prior to the sperm analysis. All samples were centrifuged at $1000 \mathrm{~g}$ for 10 minutes. The seminal plasma was aliquoted and frozen in liquid nitrogen until the time of TAC assay. Before centrifugation, around $500 \mu \mathrm{L}$ were frozen directly in liquid nitrogen for further assessment of sperm DNA integrity.

\section{The DNA integrity test}

Sperm DNA damage was evaluated by flow cytometry after staining with acridine orange. On the day of analysis, the samples were defrosted and tested immediately. All buffers and samples were kept at 4 to $6 \mathrm{C}^{0}$ and the test was run in a box with ice. After washing with TNE $(0.15 \mathrm{M} \mathrm{NaCL}$, $0.01 \mathrm{M}$ TrisHCL, 1mM EDTA, pH 7.4) buffer, the sperm concentration was adjusted to approximately $1-2 \times 10^{6}$ cells $/ \mathrm{ml}$ and $200 \mu \mathrm{L}$ of the sample was placed in $12 \times 75$ flowcytometer tubes. After that $400 \mu \mathrm{l}$ of low-pH (pH 1.2) detergent solution containing $0.1 \%$ Triton X-100, $0.15 \mathrm{M} \mathrm{NaCl}$ and $0.08 \mathrm{M} \mathrm{HCl}$ was added for 30 sec., immediately followed by $1.2 \mathrm{ml}$ staining buffer (phosphate-citrate buffer, $\mathrm{pH}$ 6.0) with 6 $\mathrm{mg} / \mathrm{l}$ acridine orange (AO;chromatographically purified; cat. No.318337-1G, Sigma-Aldrich, USA). Cells were acquired were analysed using a FACScan flowcytometer (Becton Dickinson). A total of 5000 events were accumulated for each measurement at a low flow rate. A $488 \mathrm{~nm}$ light source was used. The study of the sperm 
chromatin is based on the properties of metachromatic acridin orange (AO) staining. Acridin orange emits green light upon binding to double-stranded DNA (native) and red light when binding to a single-stranded DNA.

Data was analyzed by FlowJo software (TreeStar, Inc, Ashland, OR). Computer gates are used to determine the proportion of spermatozoa with increased levels of red fluorescence and green fluorescence. The results were presented as a percentage of sperm DNA fragmentation index (DFI).

\section{The total antioxidant capacity assay of human seminal plasma}

Semen samples were collected and all samples were centrifuged at $1000 \mathrm{~g}$. Seminal plasma was stored in liquid nitrogen for analysis. Seminal plasma total antioxidant luminometric measurement was done using the luminescent NWLSSTM Total Antioxidant Capacity kit (TAC-Peroxyl Assay)-AMS Biotechnology, UK. TAC kit is an artificial system where biologically relevant peroxyl free radicals are generated by thermal decomposition of 2.2'azobis(2 amidinopropane; ABAP) [2, 3]. These peroxyl radicals react with an indicator molecule, luminol [LH2], to generate a luminol radical $(\mathrm{LH})$ that results in emission of blue light centered at $425 \mathrm{~nm}$. When nonenzymatic antioxidants are present, luminescence is inhibited until the antioxidants are exhausted. The time of inhibition or the induction time to light production is directly proportional to the total concentration of antioxidants. The antioxidant concentration is determined by comparing induction time to that of a watersoluble Vitamin E (tocopherol) analog Trolox.

Duplicate samples were run in 96-white microplates well provided with the test kit for 250 cycles, 17 secs each. Antioxidant capacity of original sample was determined using the following formula: $(\mathrm{S}$ original $)=(\mathrm{S}$ assay $) *$ (Dilution Factor). The dilution factor for semen plasma was 40x. (Fig. 1) The results were analyzed with MARS data analysis software.

\section{Statistical analysis}

Statistical analysis was performed using Statgraphics plus 2.1 software for Windows. The data were presented as mean \pm standard deviation (mean $\pm \mathrm{SD}$ ). Statistical significance was set at $\mathrm{p} \leqslant 0.05$.

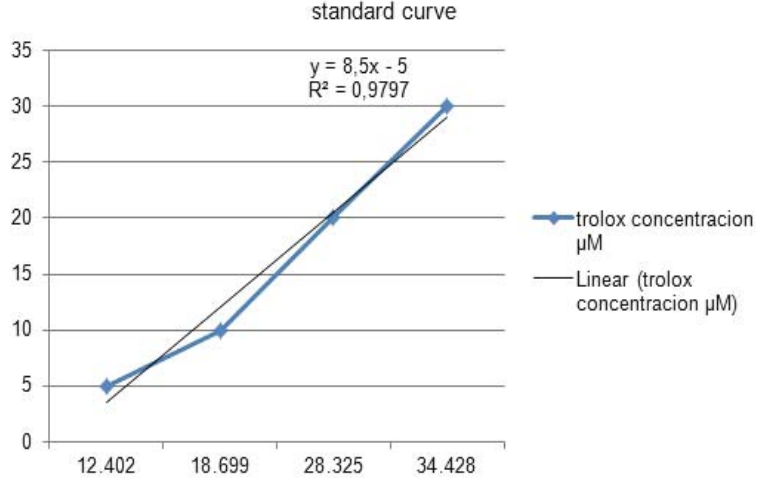

Figure 1. Standard curve for TAC measurement. Standard Trolox concentrations are represented on the $\mathrm{y}$-axis and the absorbance at the $\mathrm{x}$-axis

\section{Results}

Fertile patients were men, who had achieved pregnancy in a couple less than one year before analysis or the female partner was pregnant at the moment of analysis up to $12 \mathrm{w.g}$. (Table 1). The infertile patients were men of a sexually active noncontracepting couple that had not achieved pregnancy within one year (Table 2).

The results from sperm morphology of fertile patients showed a mean percentage of $4.8 \%$ $(\mathrm{SD} \pm 2.0)$, while this percentage was $2.8 \%$ $(\mathrm{SD} \pm 1.68)$ in the infertile group $(\mathrm{p}=0.001)$. The same group of samples, analyzed for DNA damage showed a mean of DFI $10.38 \%$ $(\mathrm{SD} \pm 5.17 \%)$ for the fertile group, and a mean $\mathrm{f}$ DFI $17.22 \%(\mathrm{SD} \pm 7.22 \%)$ for the infertile one. The TAC level found for the fertile group was $1201.1 \mu \mathrm{M}(\mathrm{SD} \pm 548)$ and in the infertile group the level was $831 \mu \mathrm{M}(\mathrm{SD} \pm 343)$.

The study did not establish a statistically significant correlation between the percentage of sperm motility and sperm concentration in both two groups.

The percentage of sperm morphology $(p=0.001)$ and TAC $(p=0.0048)$ in the group of fertile patients were significantly higher than those in the infertile patients.

The same group of samples, analyzed for DNA damage showed a mean of DFI $10.38 \%$ $(\mathrm{SD} \pm 5.17 \%)$ for the fertile men and a mean of DFI $17.22 \%$ ( $\mathrm{SD} \pm 7.22 \%$ ) for the infertile men, i.e. there was a significant correlation $(\mathrm{p}=0.009$; Fig. 2).

The TAC for the fertile group was $1201.1 \mu \mathrm{M}$ $(\mathrm{SD} \pm 548)$ and in the infertile group was $831 \mu \mathrm{M}$ $(\mathrm{SD} \pm 343)(\mathrm{p}=0.004$; Fig. 3$)$. 
Table 1. Summary statistics of basic semen parameters, DNA integrity test and TAC of fertile patients

\begin{tabular}{lccc}
\hline Fertile parameter & № & Mean \pm SD & Range \\
\hline Age [y] & 50 & $36.81 \pm 4.59$ & $30.00-46.00$ \\
\hline Concentration $[\mathbf{x} \mathbf{1 0} / \mathbf{m I}]$ & 50 & $62.10^{6} \pm 3.52$ & $6.20-120.00$ \\
\hline Motility [a+b] \% & 50 & $39.9 \pm 5.35$ & $32.00-54.00$ \\
\hline Morphology \% & 50 & $4.8 \pm 2.0$ & $2.00-8.00$ \\
\hline DFI \% & 50 & $10.38 \pm 5.17$ & $4.00-19.30$ \\
\hline TAC $[\boldsymbol{\mu} / \mathbf{m}]$ & 50 & $1201.1 \pm 548$ & $471.00-1196.00$ \\
\hline
\end{tabular}

Table 2. Summary statistics of basic semen parameters, DNA integrity test and TAC of infertile patients

\begin{tabular}{lccc}
\hline Infertile parameter & o & mean \pm SD & Range \\
\hline Age $[\mathbf{y}]$ & 50 & $35.90 \pm 5,75$ & $26.00-45.00$ \\
\hline Concentration $[\mathbf{x} \mathbf{1 0} / \mathbf{m l}]$ & 50 & $50.60 \pm 4.50$ & $6.90-120.00$ \\
\hline Motility [a+b] \% & 50 & $35.00 \pm 12.20$ & $01.00-53.00$ \\
\hline Morphology \% & 50 & $2.8 \pm 1.60$ & $1.00-6.00$ \\
\hline DFI \% & 50 & $17.22 \pm 7.20$ & $5.00-28.00$ \\
\hline TAC $[\boldsymbol{\mu} / \mathbf{m}]$ & 50 & $831 \pm 343$ & $250.00-1136.00$ \\
\hline
\end{tabular}

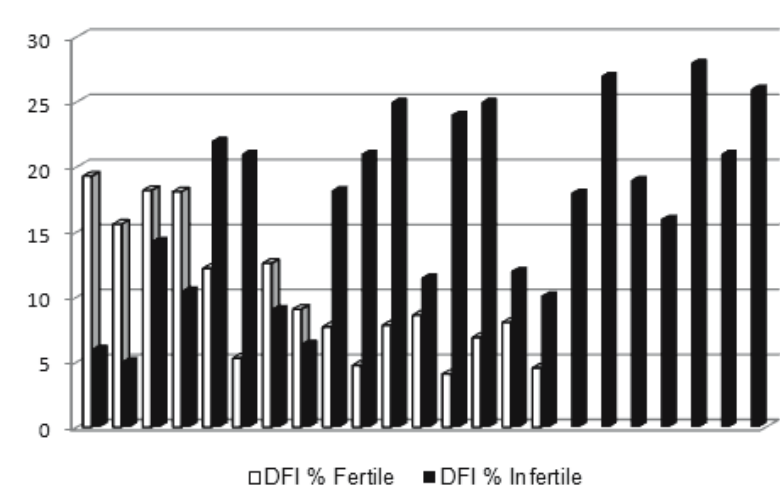

Figure 2. The sperm DNA integrity test values $[\mathrm{DFI}]$ in the infertile patient group versus the fertile group

\section{Discussion}

The pathogenetic relationship between ROS and the male infertility has been established [19-21]. Total antioxidant capacity of semen plasma provides protection from generating ROS. Therefore, when seminal total antioxidant

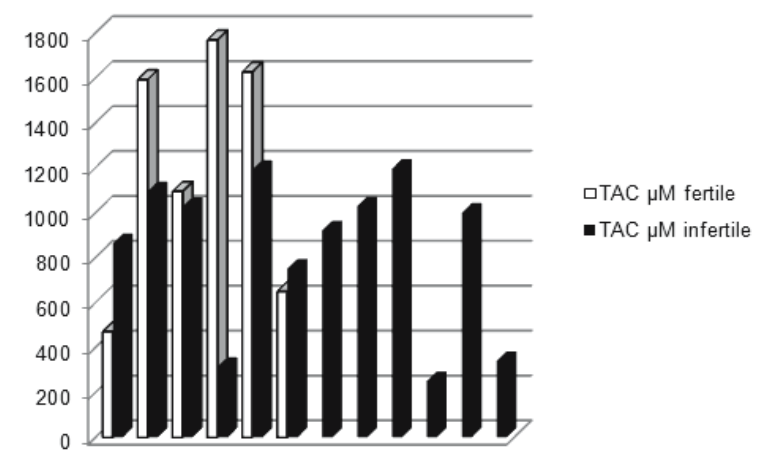

Figure 3. The seminal plasma TAC values in the infertile patient group versus the fertile patients group

capacity decreases, male fertility also decreases. Other factors such as nutrition, vitamin supply, age, and infection have been reported to influence antioxidant capacity may be influenced by the factors such as $[20,17]$. These factors were not considered in the process of patient selection in our study. 
In our study, TAC levels established for the infertile patient group showed lower values, as compared to those in the fertile men group. (Fig. 2, Fig. 3)]. The males from the fertile group showed normal sperm morphology and lower DFI levels, while the infertile group showed significantly lower levels of TAC and high levels of DNA fragmentation. We also established a cutoff value of DFI $(16 \%)$ in the fertile group. That is why we believe that DFI value should also be considered in patients with normal sperm parameters and failure to achieve natural pregnancy.

There are three main mechanisms related to damage of sperm chromatin: oxidative stress, defective chromatin packaging, and apoptosis [22]. Immature sperm, by producing high levels of ROS, can induce DNA damage in mature spermatozoa during their comigration from the seminiferous tubules to the cauda epididymis. This process activates sperm caspases and endonucleases by ROS [21, 23-26]. High levels of ROS decrease the total antioxidant capacity, thus causing seminal oxidative stress.

Some authors have reported high levels of ROS in semen samples of $25-40 \%$ of infertile men studied. High levels of ROS in seminal plasma is involved in altering plasma membrane through lipid peroxidation. Sperm cells are highly sensitive to damage induced by ROS because of the high content of polyunsaturated fatty acids in their plasma membranes and low concentration of ROS-neutralizing enzymes within the cytoplasm $[19,20]$. On the other hand, DNA damage was found to result in impaired sperm morphology, lower motility, which eventually led to male infertility $[18,19]$.

Human semen contains many types of cells, such as mature and immature spermatozoa, round cells, leukocytes and epithelial cells. Leukocytes and immature spermatozoa are the main producers of $\operatorname{ROS}[20,21]$. Polymorphonuclear cells induce ROS in response to various stimuli such as chemicals and bacteria, and this process reduces the ability of reparative systems to compensate for the DNA damage. A pathological high ROS level is a concept that needs to be more accurately determined. In future studies, it would be useful to establish reference values for TAC, taking into consideration age and presence of factors such as infection, varicocele etc.

\section{Conclusion}

Measuring total antioxidant capacity of the seminal plasma by a luminometric assay is a reliable test in diagnosing and management of male infertility. This method, however, is hardly applicable in routine practice. Total antioxidant capacity provides more relevant information than that obtained by measuring the individual components of the antioxidant capacity because it considers the cumulative effect of all components of in the semen. Measurement of TAC can more accurately determine fertility and infertility. In addition, such a test can help select sub-groups of patients with infertility, who are found with high levels of oxidative stress and who might benefit from antioxidant supplementation.

\section{Acknowledgements}

The assistance of associate professor Pavel Rashev, PhD - Institute of Biology and Immunology of reproduction - Sofia and Roumen Kotzev, urologist, University Hospital Pleven, is gratefully acknowledged. This study was supported as scientific research project [no.3 -2013] of Medical University-Pleven.

\section{References}

1. ESHRE. Unexplained infertility: Proceedings of a Human Society Reproduction workshop. Hum Reprod 1992;8:977-80.

2. Aitken RJ, Clarkson JS. Cellular basis of defective sperm function and its association with the genesis of reactive oxygen species by human spermatozoa. J Reprod Fertil. 1987;81(2):459- 69.

3. Agarwal A, Saleh RA. Role of oxidants in male infertility: rationale, significance, and treatment. Urol Clin North Am. 2002;29(4):817-27.

4. Agarwal A, Saleh RA, Bedaiwy MA. Role of reactive oxygen species in the pathophysiology of human reproduction. Fertil Steril. 2003;79(4):82943.

5. Donnelly ET, McClure N, Lewis SE. Antioxidant supplementation in vitro does not improve human sperm motility. Fertil Steri.1 1999;72(3):484-95.

6. Fingerova H, Novotny J, Barborik J, Brezinova J, Svobodova M, Krskova M, et al. Antioxidant capacity of seminal plasma measured by TAS Randox. Biomed Pap Med Fac Univ Palacky Olomouc Czech Repub. 2007;151(1):37-40. 
7. Kolettis PN, Sharma RK, Pasqualotto FF, Nelson D, Thomas AJ Jr, Agarwal A. Effect of seminal oxidative stress on fertility after vasectomy reversal. Fertil Steril. 1999;71(2):249-55.

8. Aitken RJ. The Amoroso lecture. The human spermatozoon - a cell in crisis? J Reprod Fertil. 1999;115(1):1-7.

9. Aitken RJ. A free radical theory of male infertility. Reprod Fertil Dev. 1994;6(1):19-23.

10. Gagnon C, Iwasaki A, De Lamirande E, Kovalski N. Reactive oxygen species and human spermatozoa. Ann N YAcad Sci. 1991;637:436-44.

11. Iwasaki A, Gagnon C. Formation of reactive oxygen species in spermatozoa of infertile patients. Fertil Steril. 1992;57(2):409-16.

12. O'Neill DA, McVicar CM, McClure N, Maxwell P, Cooke I, Pogue KM, et al. Reduced sperm yield from testicular biopsies of vasectomized menis due to increased apoptosis. Fertil Steril. 2007;8794):834-41.

13. Bedaiwy M, Agarwal A, Said TM, Goldberg JM, Sharma RK, Worley S, et al. Role of total antioxidant capacity in the differential growth of human embryos in vitro. Fertil Steril. 2006;86(2):304-9.

14. Pasqualotto FF, Sundaram A, Sharma RK, Borges E Jr, Pasqualotto EB, Agarwal A. Semen quality and oxidative stress scores in fertile and infertile patients with varicocele. Fertil Steril. 2008;89(3):602-7.

15. Sikka SC, Rajasekaran M, Hellstrom WJ. Role of oxidative stress and antioxidants in male infertility. J Androl 1995;16(6):464-8.

16. Zini A, Garrels K, Phang D. Antioxidant activity in the semen of fertile and infertile men. Urology. 2000;55(6):922-6.

17. Agarwal A, Prabakaran S, Allamaneni SS. Relationship between oxidative stress, varicocele and infertility: a meta-analysis. Reprod Biomed Online 2006;12(5):630-3.
18. World Health Organization, Department of Reproductive Health and Research. WHO laboratory manual for the examination and processing of human semen. 5th ed. Switzerland: WHO; 2010.271 p.

19. Saleh RA, Agarwal A, Nada EA, El-Tonsy MH, Sharma RK, Meyer A, et al. Negative effects of increased sperm DNA damage in relation toseminal oxidative stress in men with idiopathic and male factor infertility. Fertil Steril. 2003;79(Suppl 3):1597-605.

20. Agarwal A, Prabakaran SA. Mechanism, measurement, and prevention of oxidative stress in male reproductive physiology. Indian J Exp Biol. 2005;43911):963-74.

21. Sharma RK, Pasqualotto AE, Nelson DR, Thomas AJ Jr, Agarwal A. Relationship between seminal white blood cell counts and oxidative stress in men treated at an infertility clinic. J Androl. 2001;22(4):575-83.

22.Sakkas D, Alvarez JG. Sperm DNA fragmentation: mechanisms of origin, impact on reproductive outcome, and analysis. Fertil Steril. 2010;93(4):1027-36.

23. Lipshultz LI, Howards SS, Niederberger CS, editors. 4th ed. Infertility in the Male. New York: Cambridge University Press; 2009.

24. Saleh RA, Agarwal A, Kandirali E, Sharma RK, Thomas AJ, Nada EA, et al. Leukocytospermia is associated with increased reactive oxygen species production by human spermatozoa. Fertil Steril. 2002;78(6):1215-24.

25. Cummins JM, Jequier AM, Kan R. Molecular biology of human male infertility: links with aging, mitochondrial genetics, and oxidative stress? Mol Reprod Dev. 1994;37(3):345-62.

26. Aitken J, Fisher H. Reactive oxygen species generation and human spermatozoa: the balance of benefi t and risk. Bioessays. 1994;16(4):259-67. 